OPEN ACCESS

Edited by:

Silvia Salcuni,

Università Degli Studi di Padova, Italy

Reviewed by:

Osman Sabuncuoglu,

Marmara University, Turkey

Andrew Leung Luk,

Nethersole Institute of Continuing

Holistic Health Education (NICHE),

Hong Kong

*Correspondence: Alessandra Babore

a.babore@unich.it

Specialty section:

This article was submitted to

Children and Health,

a section of the journal

Frontiers in Public Health

Received: 17 September 2018 Accepted: 22 November 2018

Published: 07 December 2018

Citation:

Trumello C, Candelori C, Cofini M, Cimino S, Cerniglia L, Paciello $M$ and

Babore A (2018) Mothers

Depression, Anxiety, and Mental Representations After Preterm Birth: A

Study During the Infant's

Hospitalization in a Neonatal Intensive Care Unit. Front. Public Health 6:359.

doi: 10.3389/fpubh.2018.00359

\section{Mothers' Depression, Anxiety, and Mental Representations After Preterm Birth: A Study During the Infant's Hospitalization in a Neonatal Intensive Care Unit}

\author{
Carmen Trumello ${ }^{1}$, Carla Candelori ${ }^{1}$, Marika Cofini ${ }^{1}$, Silvia Cimino ${ }^{2}$, Luca Cerniglia ${ }^{3}$, \\ Marinella Paciello ${ }^{3}$ and Alessandra Babore ${ }^{1 *}$
}

'Department of Psychological, Health and Territorial Sciences, Università degli studi G.D'Annunzio Chieti Pescara, Chieti, Italy, ${ }^{2}$ Department of Dynamic and Clinical Psychology, Faculty of Psychology, Sapienza University of Rome, Rome, Italy, ${ }^{3}$ Università Telematica Internazionale Uninettuno, Rome, Italy

Aim: This paper aimed to explore psychological functioning and mental representations in mothers of preterm infants during the child's hospitalization in a Neonatal intensive care unit (NICU).

Methods: A sample including 62 mothers of premature infants (gestational age $<37$ weeks) was recruited in a NICU. According to the gestational age at the time of delivery, we considered two groups: Group A included mothers whose children were born before 32 weeks of pregnancy; Group B included mothers whose children were born at or after 32 weeks of pregnancy.

Within one week of childbirth, mothers were administered two self-report questionnaires: the Edinburgh Postnatal Depression Scale (EPDS) and the State-Trait Anxiety Inventory (STAI). When their infants' medical conditions became stable, the Clinical Interview for Parents of High-Risk Infants (CLIP) was administered to mothers.

Results: The results showed high levels of depression and anxiety in both groups of mothers, with higher state anxiety scores in Group A than Group B. Besides, a series of hierarchical regression analyses were conducted with STAI, EPDS, and gestational age as predictors on the CLIP scores. Results indicated that EPDS scores predicted CLIP scores on parental self-image, support system, and readiness for discharge $(p<0.001)$; moreover, the interaction among depression, anxiety, and gestational age predicted the CLIP dimension of feeling of mutual recognition $(p<0.005)$.

Conclusions: These findings suggested that a premature birth and the child's hospitalization might exert a negative effect on the mothers' emotional state, their perception of parental self-image and, consequently, the early bond with the child-independent from the infants' gestational age at the time of the preterm delivery. 
The data underlined the importance of involving NICU nurses and clinicians in order to optimize the care for mothers immediately after the preterm birth and during the infant's hospitalization, taking into account psychological needs of mothers of both very preterm and moderately preterm infants.

Keywords: neonatal intensive care unit, mothers, prematurity, maternal representations, depression, anxiety

\section{INTRODUCTION}

Preterm birth is an important issue in public health and is a major part of worldwide neonatal mortality and morbidity (1). Research has shown that premature birth is a distressing event for parents that often report symptoms of post-traumatic stress for several years $(2,3)$. Latva et al. (4) have shown that even 5 or 6 years after the preterm birth, mothers might have negative views of their perinatal or postnatal period. Otherwise, it is reported that mothers with positive experiences after a preterm birth have a more effective mother-child communication than those mothers who have had negative experiences (5). Parents of preterm infants face various difficulties and sudden changes in the process of bonding with their baby. Bonding with infants begins before birth and develops after it, but if the birth occurs sooner than expected or even too early, the normal bonding process could be affected. Goldberg and Divitto (6) have demonstrated that a long stay in hospital might have a disturbing effect on the bonding process. Although in the last decade the Neonatal Intensive Care Units (NICU) have undergone some changes for facilitating the presence of parents during the hospitalization of their baby, NICU remains a stressful environment for parents, as demonstrated in many studies (7). The physical environment is characterized by monitoring equipment, tubes and wires connected to infant, noises, and chemical scents. However, the major stress experienced by parents is related to the separation from their baby and to the loss of their parental role as they had previously imagined it. As suggested by Flacking et al. (8), the feelings of separation and exclusion could be related to the lack of physical and emotional closeness which are important factors in the early relationship between parents and the newborn infant. In fact, as frequently reported in the literature, the first moments of postpartum period are fundamental for the construction of early parent-infant bonding $(9,10)$. During hospitalization of their baby, mothers may experience several and often contradictory emotional reactions, such as grief, sadness, guilt, fear, anger, loss of self-esteem, and sense of failure (11). In fact, this situation can be so overwhelming for mothers that they might react by emotionally distancing themselves from their children $(12,13)$. These emotional factors might negatively affect the mothers' ideas, thoughts, and representations about the child's appearance and behavior. In particular, mothers of preterm babies often have fewer positive ideas and expectations for their children than mothers of term babies $(14,15)$; these could be characterized by a

Abbreviations: CLIP, Clinical Interview for Parents of High-Risk Infants; EPDS, Edinburgh Postnatal Depression Scale; NICU, Neonatal Intensive Care Unit; STAI, State-Trait Anxiety Inventory. communication about their child, generally positive, with specific and sensitive details about care (16). Crawford and Benoit's work (17) has shown that maternal representations could be influenced so much by traumatic events that the parent might become incapable of understanding their child's state of mind. So, when the child makes signals or expresses desires or needs, the parent might be unable to respond in a caring and appropriate way (18). As Deklyen and Greenberg's research (19) indicated, when this occurs, it constitutes a severe risk factor for mother-child relationship and for later psychopathology. Hall et al. (20) have shown that mothers, characterized by negative and unrealistic perceptions about their baby and the hospital environment, are often more intrusive, more withdrawn, and less sensitive toward the 6-month-old infants. In light of the aforementioned factors that might negatively affect the early postpartum periodconsidered the "sensitive time" (10) for mother-child bonding-it is very important to explore the mothers' emotional experience after a premature birth and during the hospitalization in the NICU. For this purpose, a useful tool that specifically explores parents' experience in NICU is the Clinical Interview for Parents of High-Risk Infants [CLIP; (21)]. The CLIP allows parents to reflect on and express their feelings and concerns; it could be useful to analyze the maternal representations after a preterm delivery and to detect early disruptions in the mother-infant relationship at the nursery $(5,22)$. Several studies have investigated the psychological symptoms in mothers of premature infants in terms of the symptoms of depression and anxiety. In fact, mothers of premature infants generally show higher rates of postpartum depression than mothers of full-term infants $(23,24)$. In literature, there is a broad consensus that early depressive symptoms of mothers have a negative effect on their relationship with the infant and on their parenting role, especially after a preterm birth (25). Mothers with depressive symptoms show negative perceptions of themselves, their baby, and their relationship $(26,27)$. Although most studies about the effects of mothers' postnatal mood on child development focus above all on postpartum depression, in the last decades, researchers have found that postpartum anxiety has independent effects, just as postpartum depression (28). In case of premature birth, mothers show high levels of anxiety symptoms $(24,29)$ that might compromise the maternal functions and the motherinfant interactions $(30,31)$. Besides, as Lotterman et al. (32) noticed in their recent study, a lot of research that explores psychological symptoms (including depression and anxiety) and the experience of mothers with premature infants in NICU, focuses mainly on very preterm gestational age range. Compared to this field of research, studies on moderate-to late preterm infants are less, although this gestational age range characterizes 
a high percentage of preterm births. Moreover, as far as we know, a few studies have compared maternal representations of moderately preterm and very preterm infants in the NICU during the first moments after birth. Despite the outcomes of very preterm birth are increasingly acknowledged, less attention is given to parents of moderately preterm infants. Furthermore, it remains unclear which specific factors could be most predictive of the quality of maternal representation in the NICU. Starting from the above considerations, our study aimed to more deeply explore the maternal and emotional experience in terms of mental representations, as reflected in the CLIP interview, considering depression, anxiety symptoms, and gestational age at the time of delivery.

\section{MATERIALS AND METHODS \\ Objectives}

This paper overall aimed to explore differences in psychological functioning and mental representations of the infant and themselves as parents between mothers of moderately preterm infants and mothers of very preterm infants. In order to differentiate the two groups, we have referred to recent research that set the turning point at 32 weeks of gestational age $(33,34)$.

In particular, the current study considered two groups: Group A included mothers whose children were born before 32 weeks of pregnancy (very preterm); Group B included mothers whose children were born at or after 32 weeks of pregnancy (moderately preterm). The study had the following specific objectives:

a) To verify whether Group A and Group B differ with regards to the possible presence of anxiety and depressive symptoms in mothers;

b) To verify whether Group A and Group B differ with regards to the mothers' representations about the delivery and their relationship with the premature child;

c) To verify whether the mothers' anxiety and depressive symptoms predict the quality of their representations of the child and of themselves as parents, considering gestational age.

\section{Participants}

Our study is part of a longitudinal project in which mothers and fathers of preterm infants were followed since the hospitalization in NICU till up to 2 years post-partum.

The participants were 62 mothers of preterm babies born before 37 weeks of gestation recruited in NICU of the Chieti University Hospital with the Director's, pediatricians', and nurses' collaboration. Inclusion criteria were: absence of child's genetic illnesses, neonatal deformities, and neurological damages clinically identifiable at birth, mother's age at least 18-year-old, mother's good knowledge of the Italian language, and absence of mother's drug or alcohol addiction.

Maternal and infants' basic characteristics are shown in Table 1. All parents were Caucasian and most (79\%) were of middle socio-economic status [SES; (35)]. A majority (95\%, $N=59)$ of the parents lived together, $80.6 \%(N=50)$ of the mothers were employed, and $69.4 \%(N=43)$ of the children were
TABLE 1 | Maternal and infant characteristics at NICU $(N=62)$.

\begin{tabular}{lccr}
\hline Characteristics & Frequency (\%) & M & SD \\
\hline MOTHERS & & 33.98 & 4.76 \\
Age & & 14.62 & 3.30 \\
Education (Years) & $8(13.6 \%)$ & \\
Middle school & $34(54.6 \%)$ & \\
High school & $20(31.8 \%)$ & \\
University & & \\
Maternity & $43(69.4 \%)$ & \\
Primipara & $19(30.6 \%)$ & \\
Multipara & & \\
Currently Employed & $50(80.6 \%)$ & \\
Yes & $12(19.4 \%)$ & \\
No & & \\
Marital Status & $59(95 \%)$ & \\
Married or cohabitating & $3(5 \%)$ & \\
Not married or cohabitating & & \\
INFANTS & & \\
Gender & & \\
Male & & \\
Female & & \\
Gestational Age (In Weeks) & & \\
$<32$ weeks & & \\
Birth weight (gr) & & \\
\hline & & \\
\end{tabular}

firstborn. The mean age of the mothers was 33.98 years (standard deviation $[\mathrm{sd}]=4.76)$. The children were $45 \%(N=28)$ males and $55 \%(N=34)$ females.

\section{Procedures and Measures}

Within one week after the childbirth, a group of trained psychologists administered the mothers a demographical and anamnestic form and two self-report questionnaires: Edinburgh Postnatal Depression Scale [EPDS, (36)], State-Trait Anxiety Inventory [STAI, (37)].

The EPDS is a uni-dimensional self-reported checklist, designed as a screening tool for identifying mothers at risk for post-partum depression in community settings. Subjects were asked to rate their symptoms in the past seven days on one of four response categories ranging from " 0 " = "not at all" to " 3 " = "most of the time/quite often." The possible scores, after reversing all positive-worded items, ranged from 0 to 30 with a higher score reflecting a higher risk for post-partum depression (PPD). In the present paper, we used the Italian validated version and its related cut-off, i.e., 8/9 (38).

The STAI is a self-report anxiety behavioral instrument consisting of two separate 20 -item subscales that measure trait (baseline) and state (situational) anxiety in adults. The STAI trait subscale measures relatively stable individual differences in their proneness to anxiety (i.e., differences in the tendency to experience anxiety), and the STAI state subscale measures transitory anxiety state (i.e., subjective feelings of apprehension, 
tension, and worry that vary in intensity and fluctuate based on the situation). In this paper, we used the Italian validated version and its related cut-off, i.e., 39/40 (39).

For the second step, when the infants' medical conditions were stable, a clinical interview [CLIP, (21)] was administered to the mothers by a second group of psychologists who were blind to its administration and the results of self-report questionnaires.

The CLIP was originally developed by the authors to assess the feelings and perceptions of preterm children's parents. It consists of a semi-structured interview allowing the clinician to extensively explore the parental experience. Further, its flexibility allows the clinician to adapt the questions according to the conversational flow, to better explore the parent's emotional experience. This interview requires about $1 \mathrm{~h}$ to be completed and addresses eight main areas: infant's current condition, pregnancy course, labor and delivery, relationship with the baby and feelings as a parent, reactions to NICU environment and staff, relationship with the family and social support, discharge and beyond, and a final wrapping up.

The CLIP is audio-recorded and transcribed verbatim; the authors recommended coding the interview through a content analysis; afterwards, Keren et al. (5) developed a coding system to analyze two areas: "readiness for parenthood" and "parental rejection."

Clinical interviews were administered in an empathetic and understanding environment. The interviews lasted an average of $1 \mathrm{~h}$ and were audio-recorded with the mothers' permission and subsequently transcribed verbatim, as previously indicated by the authors.

After administering all the measures, two sub-groups were created on the basis of gestational age (33, 34, 40, 41): Group A (very preterm) included mothers whose children were born between 28 and 31 weeks; Group B (moderately preterm) included mothers whose children were born between 32 and 36 weeks of pregnancy.

Participation in the study was voluntary. All the participants received a letter containing detailed information on the main aims of the study and signed a written informed consent. The questionnaires were alphanumerically coded in order to guarantee anonymity. In the current observational study any diagnostic process was performed; in addition, it involved women who had no history or ongoing evidence of any psychiatric illness; hence, we believe that the approval of the study by the Ethics Committee was not appropriate. Nevertheless, an additional opinion was asked to the Psychological Review Board of our Department. The Board found that all the employed procedures and measures were fully compliant with the Ethics Code of the Italian Board of Psychology - the national authority that provides ethical guidelines for research and clinical practice.

\section{Data Analysis}

Descriptive analyses attested that all variables were normally distributed. The analyses of variance (ANOVAs) were used to test significant differences between Group A and Group B scores on STAI, EPDS, and CLIP, and Bonferroni's post hoc tests were applied. The calculated $p$-values are reported with their respective $F$ statistics and degrees of freedom (df), with
TABLE 2 | Mean scores and standard deviations [M(sd)] values of STAI-Y1, STAI-Y2 and EPDS in Group A and Group B.

\begin{tabular}{lccc}
\hline & STAI-Y1 & STAI-Y2 & EPDS \\
\hline Group A & $48.55(13.68)$ & $38.27(8.64)$ & $13.05(5.25)$ \\
Group B & $42.85(12.69)$ & $37.21(10.36)$ & $11.33(5.78)$ \\
$p$ & $<0.01$ & n.s & n.s \\
\hline
\end{tabular}

values $<0.05$ being considered significant. Mean values are reported with standard deviations $\left(\mathrm{sd}_{\mathrm{s}}\right)$. Finally, a series of hierarchical regression analyses were conducted to investigate the influence of specific anxious and depressive symptoms (STAI and EPDS) on the mothers' representations about the delivery and their relationship with the premature child (CLIP). In all the analyses we conducted, the child's gender and mothers' age showed no significant effect on the variables. All analyses were performed on the SPSS software (Version 18.0).

\section{RESULTS}

\section{Differences in Group A and Group B Scores on the Symptoms of Anxiety and Depression}

An ANOVA conducted on Group A and Group B scores on STAIY1 showed a group effect $\left[\mathrm{F}_{(1,60)}=7.418 ; p<0.01\right)$. Post-hoc analysis showed that Group A has significantly higher scores than Group B on STAI-Y1 (State Anxiety) ( $p<0.01$ ); $72 \%$ of the subjects in Group A and $45 \%$ in Group B exceeded the clinical cut-off for STAI-Y1 for the Italian population (39).

An ANOVA conducted on Group A and Group B scores on STAI-Y2 showed no group effect $\left[\mathrm{F}_{(1,60)}=0.647 ; p>0.5\right]$. Although no statistically significant differences were found between the two groups on STAI-Y2 (Trait Anxiety), 36\% of subjects in Group A, and 37.5\% in Group B exceeded the clinical cut-off for STAI-Y2 for the Italian population (39).

An ANOVA conducted on Group A and Group B scores on EPDS showed no group effect $\left[\mathrm{F}_{(1,60)}=0.66 ; p>0.5\right]$. Although no statistically significant differences were found between the two groups on EPDS, $68 \%$ of subjects in Group A and 60\% in Group B exceeded the clinical cut-off for EPDS for Italian population (38).

Table 2 shows mean scores and standard deviations values.

\section{Differences in Group A and Group B Scores on the Mothers' Representations About the Delivery and Their Relationship With the Premature Child}

An ANOVA conducted on Group A and Group B scores on CLIP showed a group effect on several dimensions $(p<0.05)$. Post-hoc analysis showed that Group A had significantly higher scores than Group B on CLIP dimension of: perceived infant's current condition $\left(\mathrm{F}_{(1,60)}=0.016 ; p<0.05\right)$, first feelings toward baby $\left(\mathrm{F}_{(1,60)}=0.035 ; p<0.05\right)$, readiness for discharge $\left(\mathrm{F}_{(1,60)}=0.003 ; p<0.05\right)$, and organization of content $\left(\mathrm{F}_{(1,60)}=0.016 ; p<0.05\right)$. No other statistically significant 
TABLE 3 | Mean scores, standard deviations and $p$-values on CLIP main areas and subscales in Group A and Group B.

\begin{tabular}{|c|c|c|c|c|}
\hline CLIP main area & CLIP subscale & Group A & Group B & $p$ \\
\hline \multicolumn{2}{|c|}{ Infant's current condition } & $0.68(1.68)$ & $0.35(0.70)$ & $<0.05$ \\
\hline \multirow[t]{2}{*}{ Pregnancy } & First reaction to pregnancy & $1.32(0.65)$ & $1.18(0.45)$ & n.s \\
\hline & Planned pregnancy & $1.45(0.51)$ & $1.38(0.49)$ & n.s \\
\hline \multirow[t]{2}{*}{$\begin{array}{l}\text { Course of } \\
\text { pregnancy }\end{array}$} & $\begin{array}{l}\text { Physical and/or emotional } \\
\text { complications }\end{array}$ & $2.05(1.13)$ & $2.48(1.24)$ & n.s \\
\hline & $\begin{array}{l}\text { Timing of "pregnancy } \\
\text { feeling real" }\end{array}$ & $2.14(1.11)$ & $1.97(1.12)$ & n.s \\
\hline \multirow[t]{2}{*}{ Labor and delivery } & Readiness for delivery & $2.45(0.60)$ & $2.41(0.64)$ & n.s \\
\hline & Fear of loss during delivery & $2.32(0.65)$ & $2.05(0.57)$ & n.s \\
\hline \multirow{4}{*}{$\begin{array}{l}\text { Relationship with } \\
\text { baby and feelings } \\
\text { as a parent }\end{array}$} & First feelings toward baby & $1.55(0.60)$ & $1.20(0.41)$ & $<0.05$ \\
\hline & $\begin{array}{l}\text { Present feelings toward } \\
\text { baby }\end{array}$ & $1.33(0.48)$ & $1.15(0.36)$ & n.s \\
\hline & $\begin{array}{l}\text { Feeling of mutual } \\
\text { recognition }\end{array}$ & $1.52(0.68)$ & $1.46(0.55)$ & n.s \\
\hline & Parental self-image & $1.33(0.58)$ & $1.33(0.53)$ & n.s \\
\hline \multirow[t]{2}{*}{ Reaction to NICU } & Reaction to staff & $1.43(0.51)$ & $1.32(0.53)$ & n.s \\
\hline & Reaction to NICU setting & $1.67(0.62)$ & $1.93(0.92)$ & n.s \\
\hline Support system & & $1.32(0.48)$ & $1.30(0.46)$ & n.s \\
\hline \multirow{2}{*}{$\begin{array}{l}\text { Discharge and } \\
\text { beyond }\end{array}$} & Foreseen future for baby & $1.50(0.67)$ & $1.23(0.43)$ & n.s \\
\hline & Readiness for discharge & $1.70(0.70)$ & $1.24(0.43)$ & $<0.05$ \\
\hline \multicolumn{2}{|l|}{ Affect } & 1.68(0.65) & $1.53(0.56)$ & n.s \\
\hline \multicolumn{2}{|c|}{ Organization of content } & $1.36(0.58)$ & $1.26(0.44)$ & $<0.05$ \\
\hline \multicolumn{2}{|l|}{ Richness of content } & 1.62(0.59) & $1.46(0.60)$ & n.s \\
\hline
\end{tabular}

difference was found on the other CLIP subscales $(p>0.5)$. Table 3 shows mean scores and standard deviations values.

\section{Impact of Mothers' Anxiety and Depressive Symptoms on the Quality of Their Representations of the Child and of Themselves as Parents, With Respect to the Gestational Age}

A series of hierarchical regressions have been conducted with STAI, EPDS, and gestational age as predictors on the CLIP scores. The results showed that EPDS scores predicted CLIP scores on parental self-image, support system, and readiness for discharge $(p<0.01)$; gestational age predicts scores on the CLIP main area of course of pregnancy $(p<0.05)$; STAI-Y1 scores, interacting with gestational age, predict the CLIP main area of affect $(p<0.01)$. EPDS, interacting with STAI-Y1, STAI-Y2 scores, and gestational age, predict the CLIP subscale scores of feeling of mutual recognition $(p<0.05)$.

Table 4 shows results and values of the regression analyses (significant results only).

\section{DISCUSSION}

Premature delivery and the subsequent hospitalization in NICU are considered early adverse experiences, which could affect
TABLE 4 | Results and values of the regression analyses (significant results).

\begin{tabular}{|c|c|c|c|c|}
\hline \multirow[t]{2}{*}{ STAI/EPDS/gestational age } & \multicolumn{4}{|c|}{ CLIP main areas and subscales } \\
\hline & $\mathbf{R}^{2}$ & B & $\mathbf{t}$ & $p$ \\
\hline \multirow[t]{6}{*}{ EPDS } & \multicolumn{4}{|c|}{ Parental self-image } \\
\hline & 0.061 & 0.671 & 29.431 & $<0.001$ \\
\hline & \multicolumn{4}{|c|}{ Support system } \\
\hline & 0.031 & 0.767 & 32.123 & $<0.001$ \\
\hline & \multicolumn{4}{|c|}{ Readiness for discharge } \\
\hline & 0.045 & 0.369 & 3.475 & $<0.001$ \\
\hline \multirow[t]{2}{*}{ Gestational age } & \multicolumn{4}{|c|}{ Course of pregnancy } \\
\hline & 0.069 & 0.537 & 2.465 & $<0.05$ \\
\hline \multirow[t]{2}{*}{ STAI-Y1• gestational age } & & & Affect & \\
\hline & 0.052 & 0.613 & 2.324 & $<0.001$ \\
\hline \multirow{2}{*}{$\begin{array}{l}\text { EPDS•STAI-Y1•STAI-Y2 } \\
\text { gestational age }\end{array}$} & \multicolumn{4}{|c|}{ Feeling of mutual recognition } \\
\hline & 0.089 & 0.413 & 2.328 & $<0.005$ \\
\hline
\end{tabular}

the emotive states of mothers, their mental representations, their perceptions of infants, and their relationship in the early postpartum moments, that are assumed to be significant for maternal bonding to the infant.

Our study aimed to explore the maternal emotional states in NICU, with reference to anxiety and depressive symptoms, mental representations, and gestational age at the time of delivery.

With regard to the first aim, results showed that mothers of premature babies experience high levels of psychological distress in both the investigated groups, namely very preterm (Group A) and moderately preterm (Group B) children.

In reference to symptoms of anxiety, the mothers' scores significantly differed between the two groups. More specifically, the State Anxiety seemed to be the only one influenced by the baby's gestational age, in fact mothers in Group A showed higher anxiety levels than those in Group B.

These findings are consistent with the previous studies reporting that mothers of very preterm infants may be more concerned and worried about their babies' survival as compared to those of moderately preterm infants $(42,43)$.

On the contrary, there are no differences in Trait Anxiety levels when the two groups were compared, despite a large number of mothers of the whole sample exceeding the clinical cut-off for the Italian population (39). This result is in line with other ones that highlight elevated anxiety symptoms following a premature delivery $(44,45)$. An alternative explanation of the high levels of state anxiety in our sample may not exclude a post-traumatic state of the mothers, following the very preterm delivery. In fact, several recent studies found that posttraumatic stress represented the most common reactions after a premature childbirth $(46,47)$. However, this hypothesis could be more suitably explored in future research using the STAI alongside with other more specific tools for post-traumatic stress disorder.

If we move to consider depressive symptoms, contrary to general expectations, we do not find significant differences 
between the two groups, despite a high percentage of mothers exceeding the clinical cut-off for EPDS for the Italian population (38), regardless of the gestational age at the time of delivery. In our sample, during the infant's NICU hospitalization, maternal depressive symptoms in both the groups were equally elevated which was in line with other studies (48-51).

We may hypothesize that, in case of preterm birth, the precarious conditions of the child, the cold and sterile environment of the NICU, and the ambiguity of maternal role in the hospital setting make the mothers more vulnerable to depressive symptoms, even in the case of moderately preterm infants.

The mothers' feelings of helplessness, exclusion, and alienation could further increase the level of distress and might thus impact their transition to motherhood $(52,53)$. In fact, previous studies showed that the prevalence of postpartum depression after premature delivery can be estimated up to $70 \%$ (54-56).

Our finding of higher levels of anxiety and depressive symptoms in mothers of preterm infants is consistent with other research that explored the distress in mothers of premature infants as compared to mothers of full-term infants $(31,57,58)$.

In the literature, few studies have examined the level of symptoms immediately after birth or during NICU hospitalization. The current study has estimated maternal symptomatology during the infant's hospitalization, 1 week after delivery. Our results showed that beyond the infant's gestational age, mothers present a high risk of anxious and depressive symptomatology. Therefore, it could be important to pay close attention to mothers' emotional experiences related to premature birth since the first moments after delivery.

Since the first contact between a mother and her child takes place inside the NICU, it is very important to provide the mothers with psychological support or assistance right from birth in order to ensure their well-being and prevent future problems.

Another purpose of this research was to deeply explore the maternal representations during the NICU stay. More specifically, with regard to the second aim, mothers of very preterm infants differ from mothers of moderately preterm infants only in four areas of maternal representations, as reflected in the CLIP. Specifically, as compared to the mothers of moderately preterm infants, mothers of very preterm babies showed more negative experiences and perceptions relating to their infants and their relationship with them. In fact, these mothers were characterized by a greater "fear of loss of the baby" (a dimension related to the area of maternal perception of the child's current condition) and more negative "first feelings toward the baby." Additionally, they did not feel ready for discharge and the narratives of their representations were disorganized.

These major difficulties of mothers of very preterm children in the narrative organization of representations, their negative feelings toward the infant, and the low confidence in their role could be related to the perception of greater vulnerability of their baby, that increases their fear of loss (59). Seeing their infants as fragile and in danger in the NICU is very stressful for mothers, and it may generate an "emotive crisis" $(7,60)$.
The mothers of preterm infants often show feelings of ambivalence about their relationship with their child and feelings of unreality of "being mothers" during the NICU stay (61). In fact, in the case of very preterm infants, mothers spend more time in the NICU, where they are continuously in touch with the experience of the infants' fragility and risk of mortality (62). Living in a state of psychological and physical separation from their babies is intensified by the artificial environment of the NICU. All these early and difficult experiences could affect the development of maternal mental representations.

Finally, in reference to the third objective of the study, according to our results, depressive symptoms were the strongest predictors of the quality of maternal representations of the child and of themselves as mothers and of the child. In particular, depression seemed to predict more areas of representations with respect to the other variables we had considered. It predicted an insecure parental self-image, negative perception of support system, and lower readiness for discharge (this last area investigated the mothers' impression and expectations about homecoming and the baby's future development).

Generally, premature birth is considered a stressful and potentially traumatizing event (63) followed by the hospitalization in the NICU, where there is a prolonged separation between the mother and the infant. This situation might generate feelings of depression and the mothers' poorer psychological well-being which may lead to lesser psychological investment in relationship with the infant (15) and altered perception of both the mothers' parental role and the support system.

In addition, our findings showed that depressive symptoms, in interaction with anxiety (Trait and State) and gestational age, predict the CLIP area "feeling of mutual recognition," regarding the mothers' perception of being recognized by their children in their parental role. It could be concluded that in presence of the comorbidity of anxiety and depression, the lower the gestational age at the birth, the less the mothers feel to be recognized by their infants.

As suggested by Feldman (64), close proximity, nurturing, and interaction with the baby play an important role for the early mother-child interaction, consolidating mothers' confidence in her parenting role. In the NICU, these conditions are absent: the early separation between the mothers and their infants, the loss of maternal role (60), the feeling of responsibility for the unhealthy state of the infants (65), and negotiation of the infant's care with nurses and medical staff within the unit (66) are associated with a higher risk of long-term psychological problems, such as depression, anxiety, feelings of isolation, and fear for the child's well-being (67). These emotive and psychological states, with a lower gestational age, that usually requires prolonged hospitalization, seem to influence above all the aspect concerning "recognition" and "reciprocity." In fact, physical closeness represents the prerequisite for early parentto-infant bonding for maternal behaviors and for reciprocity between the mother and her child $(64,68)$. These data are in line with other research that underlined that the NICU stay could 
hinder the development of the intuitive parental capacities in the mothers of very preterm infants $(69,70)$.

Further research is needed to explore the mechanism behind the development of maternal representations in the particular situation of premature birth. Indeed, several studies have demonstrated that maternal representations influence the way in which a mother interacts with her baby (71).

Overall, our research highlights some important aspects of mothers' experience and their emotional state in the early moments of the child's life during the hospitalization in NICU in a situation of high risk for the infant.

Nevertheless, our study has some limitations, such as the small sample size and its recruitment in only one NICU; this may limit the generalizability of the results. In addition, we did not consider a comparison group of mothers with fullterm children to test depressive and anxiety levels. Hence, future research could try to replicate these findings using larger and more diversified samples, also referring to non-Italian mothers, given the wide cross-cultural variations in maternal reactions to preterm delivery.

However, the present study makes a relevant contribution to knowledge regarding the emotional state of the mothers of premature babies, highlighting a difficult emotional situation not only for the mothers of very preterm babies but also for those of moderately preterm babies. Often, it happens that high-risk mother-infant dyads receive more psychological attention than low-risk ones (5). To improve care, it is very important to also

\section{REFERENCES}

1. WHO. March of Dimes, PMnCH, Save the Children. In: Howson CP, Kinney MV, Lawn JE, editors. Born Too Soon: The Global Action Report on Preterm birth. Geneva, Switzerland: World Health Organization (2012). p. 1-124.

2. Jotzo M, Poets CF. Helping parents cope with trauma of premature birth: an evaluation of a trauma-preventive psychological intervention. Pediatrics (2005) 115:915-9. doi: 10.1542/peds.2004-0370

3. Karatzias A, Chouliara Z, Maxton F, Freer Y, Power, F. Post-traumatic symptomatology in parents with premature infants: a systematic review of the literature. J Prenatal Perinatal Psychol Health (2007) 3:249-60.

4. Latva R, Korja R, Salmelin LL, Tamminen T. How is maternal recollection of the birth experience related to the behavioral and emotional outcome of preterm infants? Early Hum Dev. (2008) 84:587-94. doi: 10.1016/j.earlhumdev.2008.02.002

5. Keren M, Feldman R, Eidelman AI, Sirota L, Lester B. Clinical interview for high-risk parents of premature infants (CLiP) as a predictor of early disruptions in het mother-infant relationship at the nursery. Infant Mental Health J. (2003) 24:93-110. doi: 10.1002/imhj. 10049

6. Goldberg S, Divitto B. Parenting children born preterm. In: Bornstein MD, editor. Handbook of parenting. Mahwah, NJ: Erlbaum (2002). p. 329-54.

7. Franck LS, Cox S, Allen A, Winter I. Measuring neonatal intensive care unit-related parental stress. J Adv Nurs. (2005) 49:608-15. doi: 10.1111/j.1365-2648.2004.03336.x

8. Flacking R, Lehtonen L, Thomson G, Axelin A, Ahlqvist S, Moran VH, et al. Closeness and separation in neonatal intensive care. Acta Paediatr. (2012) 101:1032-7. doi: 10.1111/j.1651-2227.2012.02787.x

9. Klaus MH, Kennell JH, Klaus PH. Bonding: Building the Foundations of Secure Attachment and Independence. U.S: A Merloyd Lawrence Book/ AddisonWesley Publishing Company (1995). understand the experiences of these mothers who are at the risk of being neglected. In addition, our study integrated different tools (questionnaires and interviews) and the use of a clinical interview tool - the CLIP - built specifically for parents of premature babies, that allowed us to extensively analyze maternal representations, retracing the path from pregnancy to experience in NICU with the mothers. Undeniably, not prematurity in itself but the presence of certain emotive states, negative thoughts, and perceptions in parents might be indicative of the difficulties in parent-infant relationship (72).

Parenting interventions in the NICUs play an important role in facilitating the bonding between the mother and the infant, providing support for these vulnerable families. Benzies et al. (73), in their meta-analysis, showed that early interventions in NICU decreased maternal anxiety and depressive symptoms and increased the mothers' sense of self-efficacy.

In fact, although NICU's primary function is medical assistance for infants, it is also the place where there is the first mother-child encounter and where all the early dynamics of their relationship begin. For this reason, it is crucial to conduct further research in this area.

\section{AUTHOR CONTRIBUTIONS}

All authors listed have made a substantial, direct and intellectual contribution to the work, and approved it for publication.
10. Feldman R. Sensitive periods in human social development: New insights from research on oxytocin, synchrony, and high-risk parenting. Dev Psychopathol. (2015) 27:369-95. doi: 10.1017/S0954579415000048

11. Miles MS, Holditch-Davis D. Parenting the prematurely born child: pathways of influence. Semi Perinatol. (1997) 21:254-66. doi: 10.1016/S0146-0005(97)80067-5

12. Müller-Nix C, Ansermet F. Prematurity risk factors and protective factors. In: Zeanah CH, editor. Handbook of Infant Mental Health. New York, NY: The Guilford Press (2009). p. 180-96.

13. Shah PE, Clements M, Poehlmann J. Maternal resolution of grief after preterm birth: implications for infant attachment security. Pediatrics (2011) 17:284-92. doi: 10.1542/peds.2010-1080

14. Borghini A, Pierrehumbert B, Miljkovitch R, Muller-Nix C, Forcada-Geux, M, Ansermet, F. Mother's attachment representations of their premature infant at 6 and 18 months after birth. Infant Mental Health J. (2006) 27:494-508. doi: 10.1002/imhj.20103

15. Forcada-Guex M, Borghini A, Pierrehumbert B, Ansermet F, Müllernix C. Prematurity, maternal posttraumatic stress and consequences on the mother-infant relationship. Early Hum Dev. (2011) 87: 21-26. doi: 10.1016/j.earlhumdev.2010.09.006

16. Tooten, A. First Connections. The Impact of Preterm Birth on Mothers and Fathers. Dissertation's thesis. Tilburg University (2014).

17. Crawford A, Benoit D. Caregivers' disrupted representations of the unborn child predicts later infant-caregiver disorganized attachment and disrupted interactions. Infant Mental Health J. (2009) 30:124-44. doi: 10.1002/imhj.20207

18. Rollè L, Prino LE, Sechi C, Vismara L, Neri E, Polizzi C, et al. Parenting stress, mental health, dyadic adjustment: a structural equation model. Front Psychol. (2017) 8:839. doi: 10.3389/fpsyg.2017.00839

19. Deklyen M, Greenberg MT. Attachment and psychopathology in childhood. In: Cassidy J, Shaver PR. Handbook of Attachment: Theory, Research and Clinical Applications. New York, NY: The Guilford Press (2008). p. 637-65. 
20. Hall RA, Hoffenkamp HN, Tooten, A, Braeken J, Vingerhoets AJ, van Bakel HJ. Longitudinal associations between maternal disrupted representations, maternal interactive behavior and infant attachment: a comparison between full-term and preterm dyads. Child Psychiatry Hum Dev. (2015) 46:320-31. doi: 10.1007/s10578-014-0473-3

21. Meyer EC, Zeanah CH, Boukydis CFZ, Lester BM. A clinical interview for parents of high-risk infants: concept and applications. Infant Mental Health J. (1993) 14:192-207. doi: 10.1002/1097-0355(199323)14:3<192::AIDIMHJ2280140305>3.0.CO;2-R.

22. Candelori C, Trumello C, Babore A, Keren M, Romanelli R. The experience of premature birth for fathers: the application of the clinical interview for parents of high-risk infants (CLIP) to an Italian sample. Front Psychol. (2015) 6:1444. doi: 10.3389/fpsyg.2015.01444

23. Beck CT. Recognizing and screening for postpartum depression in mothers of NICU infants. AdvNeonatal Care (2003) 3:37-46. doi: 10.1053/adnc.2003.50013

24. Lefkowitz DS, Baxt C, Evans JR. Prevalence and correlates of posttraumatic stress and postpartum depression in parents of infants in the neonatal intensive care unit (NICU). J Clin Psychol Med Settings. (2010) 17:230-7. doi: 10.1007/s10880-010-9202-7

25. Moehler E, Brunner R, Wiebel A, Reck C, Resch F. Maternal depressive symptoms in the postnatal period are associated with long-term impairment of mother-child bonding. Arch Women's Mental Health (2006) 9:273-8. doi: 10.1007/s00737-006-0149-5

26. Ahlqvist-Björkroth S. Challenges for the Transition into Early Parenthood: Prenatal Depressive Symptoms, Marital Distress, and the Premature Birth of an Infant. Dissertation's thesis. Turku: University of Turku (2017).

27. Vismara L, Rollè L, Agostini F, Sechi C, Fenaroli V, Molgora S, et al. Perinatal parenting stress, anxiety, and depression outcomes in first-time mothers and fathers: a 3- to 6-months postpartum follow-up study. Front Psychol. (2016) 7:938. doi: 10.3389/fpsyg.2016.00938

28. Field T. Postnatal anxiety prevalence, predictors and effects on development: A narrative review. Infant Behav Dev. (2018) 51:24-32. doi: 10.1016/j.infbeh.2018.02.005

29. Feeley N, Zelkowitz P, Cormier C, Charbonneau L, Lacroix A, Papageorgiou A. Posttraumatic stress among mothers of very low birthweight infants at 6 months after discharge from the neonatal intensive care unit. Appl Nurs Res. (2011) 24:114-7. doi: 10.1016/j.apnr.2009.04.004

30. Schmücker G, Brisch KH, Köhntop B, Betzler S, Österle M, Pohlandt F, et al. The influence of prematurity, maternal anxiety, and infants' neurobiological risk on mother-infant interactions. Infant Mental Health J. (2005) 26:423-41. doi: 10.1002/imhj.20066

31. Brandon DH, Tully KP, Silva SG, Malcolm WF, Murtha AP, Turner BS, et al. Emotional Responses of Mothers of Late-Preterm and Term Infants. J Obstetr, Gynecol Neonatal Nurs. (2011) 40:719-31. doi: 10.1111/j.1552-6909.2011.01290x.

32. Lotterman JH, John M. Lorenz HM, Bonanno GA. You Can't Take Your Baby Home Yet: a longitudinal study of psychological symptoms in mothers of infants hospitalized in the NICU. J Clin Psychol Med Settings (2018) doi: 10.1007/s10880-018-9570-y. [Epub ahead of print].

33. Nordvall-Lassen M, Hegaard HK, Obel C, Lindhard MS, Hedegaard M, Henriksen TB. Leisure time physical activity in 9- to 11-year-old children born moderately preterm: a cohort study. BMC Pediatrics (2018) 18:163. doi: 10.1186/s12887-018-1141-8

34. Taine M, Charles MA, Beltrand J, Rozé JC, Léger J. et al. Early postnatal growth and neurodevelopment in children born moderately preterm or small for gestational age at term: a systematic review. Paediatr Perinatal Epidemiol. (2018) 32:268-80. doi: 10.1111/ppe.12468

35. Hollingshead AA. Four-Factor Index of Social Status. New Haven, CT: Yale University (1975).

36. Cox JL, Holden JM, Sagovsky R. Detection of postnatal depression. Development of the 10-item edinburgh postnatal depression scale. $\mathrm{Br} \mathrm{J}$ Psychiatry (1987) 150:782-6. doi: 10.1192/bjp.150.6.782

37. Spielberger CD, Gorsuch RL, Lushene RL. Manual for the State-Trait Anxiety Inventory: STAI (Self-evaluation Questionnaire). Palo Alto, CA: Consulting Psychologist Press. (1970).
38. Benvenuti P, Ferrara M, Niccolai C, Valoriani V, Cox JL. The edinburgh postnatal depression scale: validation for an Italian sample. J Affect Disord. (1999) 53:137-41. doi: 10.1016/S0165-0327(98)00102-5

39. Pedrabissi L, Santinello M. Inventario per L'ansia di Stato e di Tratto: Nuova versione Italiana Dello STAI-forma Y [Manual for the State-Trait Anxiety Inventory: New Italian Version of the STAY-Y form]. Firenze: Organizzazioni Speciali (1989).

40. Goldenberg RL, Culhane JF, Iams JD, Romero R. Epidemiology and causes of preterm birth. Lancet (2008) 371:75-84. doi: 10.1016/S0140-6736(08)60074-4

41. Sansavini A, Guarini A. Nuove prospettive di ricerca nella popolazione dei nati pretermine. In: Sansavini A, Faldella G, editor. Lo Sviluppo Dei Bambini Nati Pretermine. Aspetti Neuropsicologici, Metodi di Valutazione e Interventi. Milano: Franco Angeli (2013). p. 27-39.

42. Engle WA, Tomashek KM, Wallman C. The committee on fetus and newborn "Late-preterm" infants: a population at risk. Pediatrics (2007) 120:1390-401. doi: 10.1542/peds.2007-2952

43. Shapiro-Mendoza CK, Lackritz EM. Epidemiology of late and moderate preterm birth. Semi Fetal Neonatal Med. (2012) 17:120-5. doi: 10.1016/j.siny.2012.01.007

44. Singer LT, Salvator A, Guo S, Collin M, Lilien L, Baley J. Maternal psychological distress and parenting stress after the birth of a very low-birth-weight infant. J Am Med Assoc. (1999) 28:799-805. doi: 10.1001/jama.281.9.799

45. Misund AR, Nerdrum P, Braten S, Pripp AH, Diseth TH. Long-term risk of mental health problems in women experiencing preterm birth: a longitudinal study of 29 mothers. Ann Gen Psychiatry (2013) 12:33. doi: $10.1186 / 1744-859 \mathrm{X}-12-33$

46. Suttora C, Spinelli M, Monzani D. From prematurity to parenting stress: The mediating role of perinatal post-traumatic stress disorder. Eur J Dev Psychol. (2014) 11:478-93. doi: 10.1080/17405629.2013.859574

47. Misund AR, Nerdrum P, Diseth TH. Mental health in women experiencing preterm birth. BMC Pregnancy Childbirth (2014) 14:263. doi: 10.1186/1471-2393-14-263

48. Mew AM, Holditch-Davis D, Belyea M, Miles MS, Fishel A. Correlates of depressive symptoms in mothers of preterm infants. Neonatal Network (2003) 22:51-60. doi: 10.1891/0730-0832.22.5.51

49. Yurdakul Z, Akman I, Kuscu MK, Karabekiroglu A, Yaylali G, Demir F, et al. Maternal psychological problems associated with neonatal intensive care admission. Int J Pediatr. (2009) 591359:7. doi: 10.1155/2009/591359

50. Rogers CE, Kidokoro H, Wallendorf M, Inder TE. Identifying mothers of very preterm infants at-risk for postpartum depression and anxiety before discharge. J Perinatol. (2013) 33:171-6. doi: 10.1038/jp.2012.75

51. Vasa R, Eldeirawi K, Kuriakose VG, Nair GJ, Newsom C, Bates J. Postpartum depression in mothers of infants in neonatal intensive care unit: risk factors and management strategies. Am J Perinatol. (2014) 31:425-34. doi: 10.1055/s-0033-1352482

52. Chertok IR, McCrone S, Parker D, Leslie N. Review of interventions to reduce stress among mothers of infants in the NICU, Adv Neonatal Care (2014) 14:30-7. doi: 10.1097/ANC.0000000000000044

53. Tambelli R, Cerniglia L, Cimino S, Ballarotto G. Parent-infant interactions in families with women diagnosed with postnatal depression: a longitudinal study on the effects of a psychodynamic treatment. Front Psychol. (2015) 6:1210. doi: 10.3389/fpsyg.2015.01210

54. Younger JB, Kendell MJ, Pickler RH. Mastery of stress in mothers of preterm infants. J Soc Pediatr Nurses (1997) 2:29-35. doi: 10.1111/j.1744-6155.1997.tb00197.x

55. Davis L, Edwards H, Mohay H, Wollin J. The impact of very premature birth on the psychological health of mothers. Early Hum Dev. (2003) 73:61-70. doi: 10.1016/S0378-3782(03)00073-2

56. Miles MS, Holditch-Davis D, Scher M, Schwartz T. A longitudinal study of depressive symptoms in mothers of prematurely born infants. J Dev Behav Pediatrics (2007) 28:36-44. doi: 10.1097/01.DBP.0000257517.52459.7a

57. Voegtline KM, Stifter CA. The family life project investigators. late-preterm birth, maternal symptomatology, and infant negativity. Infant Behav Dev. (2010) 33:545-54. doi: 10.1016/j.inhbeh.2010.07.006

58. Zanardo V, Gambina I, Begley C, Litta P, Cosmi E, Giustardi A. et al. Psychological distress and early lactation performance in 
mothers of late preterm infants. Early Hum Dev. (2011) 87:321-3. doi: 10.16/j.earlhumdev.2011.01.035

59. Beck CT, Harrison L. Posttraumatic stress in mothers related to giving birth prematurely: A mixed research synthesis. J Am Psychiatric Nurs Assoc. (2017) 23:241-57. doi: 10.1177/1078390317700979

60. Alkozei A, McMahon E, Lahav A. Stress levels and depressive symptoms in NICU mothers in the early postpartum period. I Maternal-Fetal Neonatal Med. (2014) 27:1738-43. doi: 10.3109/14767058.2014.942626

61. Jackson K, Ternestedt B. Schollin J. From alienation to familiarity: experiences of mothers and fathers of preterm infants. J Adv Nurs. (2003) 43:120-9. doi: 10.1046/j.1365-2648.2003.02686.x

62. Clottey M, Dillard DM. Post-traumatic stress disorder and neonatal intensive care. Int J Childbirth Edu. (2013) 28:23-9.

63. Kersting A, Dorsch M, Wesselmann U, Ludorff K, Witthaut J, Ohrmann P. et al. Maternal posttraumatic stress response after the birth of a very low-birth-weight infant. J Psychosom Res. (2004) 57:473-6. doi: 10.1016/j.jpsychores.2004.03.011

64. Feldman-Winter L, Goldsmith JP, AAP Committee on fetus and newborn, aap task force on sudden infant death syndrome. Safe sleep and skin-toskin care in the neonatal period for healthy term newborns. Pediatrics (2016) 138:e20161889 doi: 10.1542/peds.2016-1889

65. Kawafha MM. Parental stress in the neonate intensive care unit and its association with parental and infant characteristics. J Neonatal Nurs. (2018) 24:266-72. doi: 10.1016/j.jnn.2018.05.005

66. Lupton D, Fenwick J. 'They've forgotten that I'm the mum': constructing and practising motherhood in special care nurseries. Social Sci Med. (2001) 53:1011-21. doi: 10.1016/S0277-9536(00)00396-8

67. Howe TH, Sheu CF, Wang TN, Hsu YW. Parenting stress in families with very low birth weight preterm infants in early infancy. Res Dev Disabil. (2014) 35:1748-56. doi: 10.1016/j.ridd.2014.02.015

68. Feldman R, Weller A, Leckman JF, Kuint J, Eidelman AI. The nature of the mother's tie to her infant: Maternal bonding under conditions of proximity, separation, and potential loss. J Child Psychol Psychiatry Allied Discipl. (1999) 40:929-39. doi: 10.1017/S0021963099004308
69. Papoušek H, Papoušek M. Intuitive parenting: A dialectic counterpart to the infant's integrative competence. In: Osofsky JD, editor. Wiley Series on Personality Processes Handbook of Infant Development. Oxford, England: John Wiley \& Sons (1987). p. 669-720.

70. Guillaume S, Michelin N, Amrani E, Benier B, Durrmeyer X, et al. Parents' expectations of staff in the early bonding process with their premature babies in the intensive care setting: a qualitative multicenter study with 60 parents. BMC Pediatrics (2013) 13:18. doi: 10.1186/1471-24 31-13-18

71. Tooten A, Hall RA, Hoffenkamp HN, Braeken J, Vingerhoets AJ, van Bakel HJ. Maternal and paternal infant representations: a comparison between parents of term and preterm infants. Infant Behav Dev. (2014) 37:366-79. doi: 10.1016/j.infbeh.2014.05.004

72. Hoffenkamp HN, Tooten A, Hall RAS, Braeken J, Eliëns MPJ, et al. Effectiveness of hospital-based video interaction guidance on parental interactive behavior, bonding, and stress after preterm birth: a randomized controlled trial. J Consult Clin Psychol. (2015) 83:416-29. doi: 10.1037/a0038401

73. Benzies KM, Magill-Evans JE, Hayden KA, Ballantyne M. Key components of early intervention programs for preterm infants and their parents: a systematic review and meta-analysis. BMC Pregnancy Childbirth (2013) 13:S10. doi: 10.1186/1471-2393-13-S1-S10

Conflict of Interest Statement: The authors declare that the research was conducted in the absence of any commercial or financial relationships that could be construed as a potential conflict of interest.

Copyright (c) 2018 Trumello, Candelori, Cofini, Cimino, Cerniglia, Paciello and Babore. This is an open-access article distributed under the terms of the Creative Commons Attribution License (CC BY). The use, distribution or reproduction in other forums is permitted, provided the original author(s) and the copyright owner(s) are credited and that the original publication in this journal is cited, in accordance with accepted academic practice. No use, distribution or reproduction is permitted which does not comply with these terms. 